\title{
Transposing an active fault database into a fault-based seismic hazard assessment for nuclear facilities - Part 2: Impact of fault parameter uncertainties on a site-specific PSHA exercise in the Upper Rhine Graben, eastern France
}

\author{
Thomas Chartier $^{1,2}$, Oona Scotti ${ }^{1}$, Christophe Clément ${ }^{1}$, Hervé Jomard ${ }^{1}$, and Stéphane Baize ${ }^{1}$ \\ ${ }^{1}$ Bureau d'Evaluation des Risques Sismiques pour la Sûreté des Installations, Fontenay-aux-Roses, 92262, France \\ ${ }^{2}$ Today at Département de Géosciences, Ecole Normale Supérieure, Paris, 75005, France
}

Correspondence to: Thomas Chartier (chartier@geologie.ens.fr)

Received: 9 March 2017 - Discussion started: 15 March 2017

Accepted: 15 August 2017 - Published: 20 September 2017

\begin{abstract}
We perform a fault-based probabilistic seismic hazard assessment (PSHA) exercise in the Upper Rhine Graben to quantify the relative influence of fault parameters on the hazard at the Fessenheim nuclear power plant site. Specifically, we show that the potentially active faults described in the companion paper (Jomard et al., 2017, hereafter Part 1) are the dominant factor in hazard estimates at the low annual probability of exceedance relevant for the safety assessment of nuclear installations. Geological information documenting the activity of the faults in this region, however, remains sparse, controversial and affected by a high degree of uncertainty. A logic tree approach is thus implemented to explore the epistemic uncertainty and quantify its impact on the seismic hazard estimates. Disaggregation of the peak ground acceleration (PGA) hazard at a 10000-year return period shows that the Rhine River fault is the main seismic source controlling the hazard level at the site. Sensitivity tests show that the uncertainty on the slip rate of the Rhine River fault is the dominant factor controlling the variability of the seismic hazard level, greater than the epistemic uncertainty due to ground motion prediction equations (GMPEs). Uncertainty on slip rate estimates from 0.04 to $0.1 \mathrm{~mm} \mathrm{yr}^{-1}$ results in a 40 to $50 \%$ increase in hazard levels at the 10000 -year target return period. Reducing epistemic uncertainty in future fault-based PSHA studies at this site will thus require (1) performing in-depth field studies to better characterize the seismic potential of the Rhine River fault; (2) complementing GMPEs with more physics-based modelling approaches to better account for the near-field effects of ground motion and
\end{abstract}

(3) improving the modelling of the background seismicity. Indeed, in this exercise, we assume that background earthquakes can only host $M<6.0$ earthquakes. However, this assumption is debatable, since faults that can host $M>6.0$ earthquakes have been recently identified at depth within the Upper Rhine Graben (see Part 1) but are not accounted for in this exercise since their potential activity has not yet been described.

\section{Introduction}

The Upper Rhine Graben (URG) is one of the most seismically active areas in metropolitan France, where active faulting along north-south structures has been documented in the literature (see Part 1, Jomard et al., 2017, and references therein]. The close proximity of a nuclear site to these faults, which are potential sources of $M>6.0$ earthquakes, requires setting up fault models based on the available geological information and developing tools with which to compute the seismic hazard posed by these faults in a probabilistic framework. The geological evidence of their activity and corresponding fault model are discussed in the companion paper (Part 1). The purpose of this paper is to show the shortcomings and challenges posed by the modelling of faults in probabilistic seismic hazard calculations.

Probabilistic seismic hazard assessment (PSHA) is a method classically used to assess seismic hazard for a single site or for a group of sites, hence creating a seismic hazard 
map. The first step of PSHA following a Cornell-McGuire (Cornell, 1968; McGuire, 1976) approach is the characterization of the seismic sources, including seismogenic zones and active faults. The parameters of the slow moving faults of the URG, with slip rates less than $0.1 \mathrm{~mm} \mathrm{yr}^{-1}$, are affected by large uncertainties because their recent activity is not necessarily well expressed in the landscape. In this study, we explore the range of associated uncertainties by setting up a logic tree exploring the fault parameters and uncertainties as described in the faults database (BDFA - see Part 1). For critical facilities, the PSHA needs to be calculated for low probabilities of exceedance (long return periods) of the ground motion (see International Atomic Energy Agency, IAEA 2010). We focus the discussion on the 10000 -year return period of ground motion hazard computed with the CRISIS2015 software (Ordaz et al., 2014).

\section{A fault model in a probabilistic seismic hazard assessment (PSHA)}

\subsection{Defining the geometry of fault sources and the background source}

Two types of source need to be defined in a fault-based PSHA model approach: background sources and fault sources (e.g. Fujiwara et al., 2009; Wang et al., 2016; Valentini et al., 2017). Both types of source can generate earthquakes over a wide spectrum of magnitudes. In this study we implement a very simplistic approach by allowing higher magnitude events $(M \geq 6.0)$ to occur only on faults. The delicate issue of how to properly partition earthquakes between background and fault sources is not the scope of this study and should be tackled in the future development of hazard model for the area.

The background zone was defined using the zoning scheme of Baize et al. (2013) and a homogenous $M_{\mathrm{w}}$ catalogue derived from the Laboratoire de détection géophysique (CEA/LDG, 2011) catalogue for the instrumental part, and FPEC (the IRSN contribution to SHEEC, Stucchi et al., 2013) for the historical part. The seismicity rate of the background follows a Gutenberg and Richter (1954) (GR) distribution truncated between a minimum magnitude $\left(M_{\min }\right)$ and a maximum magnitude $\left(M_{\max }\right)$. The $M_{\min }$ is fixed at 5.0 in this study, as it is commonly assumed that earthquakes below magnitude 5.0 are not damaging for nuclear installations (Bommer and Crowley, 2017). The maximum magnitude for the background is fixed at 5.9 since $M \geq 6.0$ events are assumed in this exercise to occur on faults only.

Following the BDFA (Fig. 4 of Part 1, Supplement), three fault systems are present in the site vicinity: the West Rhenish fault system limiting the URG to the west, the Rhine River fault system lying within the graben and the Black Forest fault system limiting the URG to the east. These faults are considered to be strictly normal faults in this hazard model.
In this southernmost part of the URG, BDFA points out three individualized segments for each considered fault system. In this study only single segment fault ruptures are considered; multiple fault rupture scenarios should be considered in a later study. The maximum possible magnitude that each fault segment can release is then determined with the Wells and Coppersmith (1994) empirical scaling relationship, hereafter WC94, using the mean value of the $\mathrm{a}$ and $\mathrm{b}$ coefficients for normal faults (Table 2a of Wells and Coppersmith, 1994). The surface area of each fault segment is used to calculate the maximum magnitude. Geophysical information allows us to constrain the 3-D geometry of the faults, with some uncertainty about the dip and the seismogenic depth (between 15 and $20 \mathrm{~km}$ according to the microseismicity presented by Edel et al., 2006). The slip rates of each segment are also highly uncertain, as presented in the companion paper (Part 1). In order to explore the impact of these uncertainties in the seismic hazard calculations different geometrical hypothesis and published slip rates are considered as shown in Table 1.

\subsection{Modelling seismicity on faults}

In order to compute seismic hazard related to faults it is necessary to transform their slip rates into an annual number of earthquakes per magnitude bin. In this study we consider that the entire slip rate is converted into seismic moment rate. The classical approach for converting slip rate into seismic moment rate is based on the following relationship Eq. (1):

$\dot{M}_{0}=\mu A \dot{s}$,

where $\dot{M}_{0}$ is the seismic moment rate $\left(\mathrm{Nmyr}^{-1}\right), \mu$ is the shear modulus $\left(\mathrm{Nm}^{-2}\right), A$ is the surface rupture area $\left(\mathrm{m}^{2}\right)$ and $\dot{s}$ is the slip rate $\left(\mathrm{myr}^{-1}\right)$. Then the relating moment magnitude and seismic moment $(\mathrm{Nm})$ through the Hanks and Kanamori (1979) relationship Eq. (2) are as follows:

$M_{0}=10^{(1.5 M+9.05)}$.

Finally, it is necessary to make an hypothesis about how this moment rate is released. In this study we considered only two hypotheses of magnitude frequency distribution (MFD):

- Seismic moment rate of faults is released by ruptures that involve the entire surface area of the fault and thus produces events of the same characteristic magnitude (Wesnousky, 1986) equal to the maximum magnitude defined in Table 1.

- Seismic moment rate of faults is released by different magnitudes following the Gutenberg and Richter (1954) (GR) hypothesis, which states that the expected number of earthquakes in a given region and time span will be

$N(m \geq M)=10^{(a-b M)}$, 
Table 1. Example of fault parameters considered in the calculations (seismogenic depth of $15 \mathrm{~km}$, steepest dip of the faults). FR is Rhine River fault, FFN is Black Forest fault, FRO is West Rhenish fault. (See Fig. 4 of Part 1, Jomard et al., 2017.)

\begin{tabular}{|c|c|c|c|c|c|c|}
\hline \multirow[t]{2}{*}{$\begin{array}{l}\text { Fault } \\
\text { name }\end{array}$} & \multirow[t]{2}{*}{$\begin{array}{l}\text { Length } \\
(\mathrm{km})\end{array}$} & \multirow[t]{2}{*}{$\begin{array}{l}\text { Maximum magnitude (WC94 normal fault, } \\
\text { rupture area, mean coefficients) }\end{array}$} & \multicolumn{2}{|c|}{$\begin{array}{l}\text { Dip } \\
\left({ }^{\circ}\right)\end{array}$} & \multicolumn{2}{|c|}{$\begin{array}{c}\text { Fault slip rate } \\
\left(\mathrm{mm} \mathrm{yr}^{-1}\right)\end{array}$} \\
\hline & & & Min & Max & Min & Max \\
\hline FR 1 & 36 & 6.7 & 60 & 80 & 0.04 & 0.1 \\
\hline FR 2 & 27 & 6.6 & 60 & 80 & 0.04 & 0.1 \\
\hline FR 3 & 20 & 6.5 & 60 & 80 & 0.04 & 0.1 \\
\hline FFN 1 & 15 & 6.3 & 60 & 80 & 0.05 & 0.15 \\
\hline FFN 2 & 50 & 6.9 & 60 & 80 & 0.05 & 0.15 \\
\hline FFN 3 & 35 & 6.7 & 60 & 80 & 0.05 & 0.15 \\
\hline FRO 1 & 36 & 6.8 & 40 & 60 & 0.01 & 0.05 \\
\hline FRO 2 & 16 & 6.4 & 40 & 60 & 0.01 & 0.05 \\
\hline FRO 3 & 27 & 6.7 & 40 & 60 & 0.01 & 0.05 \\
\hline
\end{tabular}
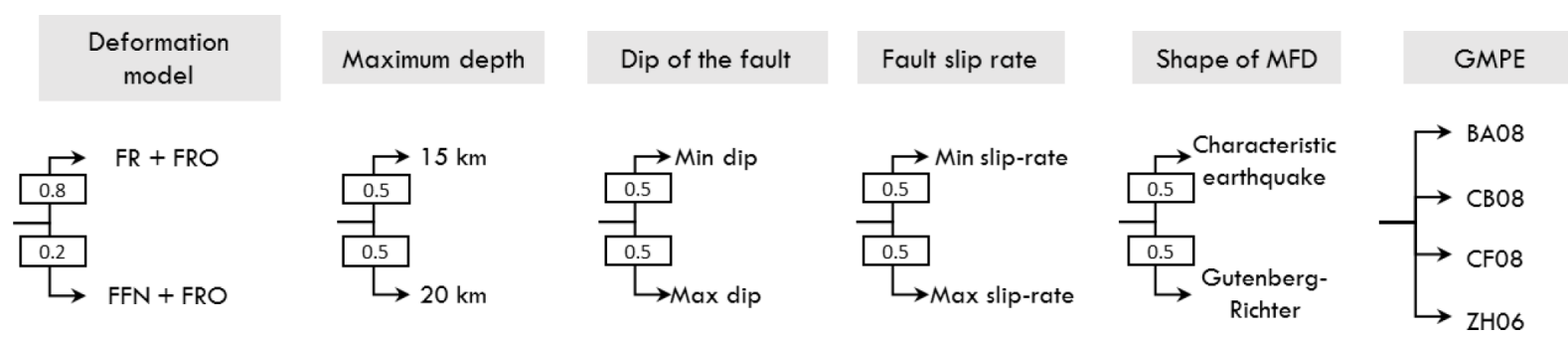

Figure 1. Logic tree explored in this study: the weight attributed to each hypothesis is shown by the number in the boxes. GMPEs are explored separately (no weight attributed).

where $M$ is the earthquake magnitude, $a$ and $b$ are constants, and $N$ is the expected number of earthquake with a magnitude $m$ greater than $M$.

In the characteristic earthquake hypothesis, the annual rate of the event $\lambda\left(M=M_{\text {characteristic }}\right)$ is deduced from the following equation:

$\lambda\left(M=M_{\text {characteristic }}\right)=\frac{\dot{M}_{0}}{M_{0}}$.

In the GR hypothesis, the MFD is defined between a value $M_{\min }$ of 6.0 , below which earthquakes occur in the background, and a value $M_{\max }$, which is the maximum magnitude possible on the fault. The rate of events of magnitudes greater than the magnitude of interest $\lambda\left(M \geq M_{\min }\right)$ is deduced from the following equation (Cosentino et al., 1977):

$$
\begin{aligned}
& \lambda\left(M \geq M_{\min }\right)=\frac{1.5-b}{b} \\
& \cdot \frac{1-10^{-b\left(M_{\max }-M_{\min }\right)}}{10^{-b\left(M_{\max }-M_{\min }\right)} \cdot\left(10^{1.5 \cdot M_{\max }+9.05}-10^{1.5 \cdot M_{\min }+9.05}\right)} \\
& \cdot \mu \cdot A \cdot \dot{s} .
\end{aligned}
$$

In this study, the slope of the GR distribution is assumed equal to $1(b=1)$ and the shear modulus is fixed at $3 \times$
$10^{10} \mathrm{Nm}^{-2}$ as a standard value. Table 2 summarizes the seismic activity of each fault considered in this exercise deduced from published slip rates and assuming either a characteristic or a GR earthquake magnitude distribution.

\section{Logic tree explored in this study}

The classical way to explore epistemic uncertainties in seismic hazard assessment is to set up a logic tree.

In this study we explore the following epistemic uncertainties (Fig. 1):

1. The localization of the deformation in the Rhine Graben: two geodynamical hypotheses are proposed in the literature: one in which deformation is accommodated essentially on the Rhine River and the West Rhenish faults and an alternative one which considers that deformation is more localized on the Black Forest and the West Rhenish faults. However, most of the authors consider that the deformation today occurs mainly within the URG and much less along the flanks of the graben (Schumacher, 2002; Rotstein and Schaming, 2011). Therefore, the branch where the deformation is accommodated along the Rhine River fault is weighted more strongly in the logic tree (0.8). 
Table 2. Example of seismic activity for each fault deduced from their slip rate and geometries (Table 1, seismogenic depth of $15 \mathrm{~km}$, steepest dip of the faults) and $\mu=3 \times 10^{10} \mathrm{Nm}^{-2}$. FR is Rhine River fault, FFN is Black Forest fault and FRO is West Rhenish fault.

\begin{tabular}{lccccr}
\hline Fault name & \multicolumn{2}{c}{$\begin{array}{c}\text { Annual rate of } M \geq 6 \text { for } \\
\text { the GR-model }\left(\# \mathrm{Ny}^{-1} \text { ) }\right.\end{array}$} & & \multicolumn{2}{c}{$\begin{array}{c}\text { Return period of the characteristic } \\
\text { earthquake (year) }\end{array}$} \\
\cline { 2 - 3 } \cline { 5 - 6 } & Min slip rate & Max slip rate & & Min slip rate & Max slip rate \\
\hline FR 1 & $1.13 \times 10^{-4}$ & $2.82 \times 10^{-4}$ & & 20773 & 8309 \\
FR 2 & $9.47 \times 10^{-5}$ & $2.38 \times 10^{-4}$ & & 17835 & 7134 \\
FR 3 & $7.85 \times 10^{-5}$ & $1.96 \times 10^{-4}$ & & 15213 & 6085 \\
FFN 1 & $8.14 \times 10^{-5}$ & $2.44 \times 10^{-4}$ & & 10449 & 3483 \\
FFN 2 & $1.70 \times 10^{-4}$ & $5.11 \times 10^{-4}$ & & 19779 & 6593 \\
FFN 3 & $1.38 \times 10^{-4}$ & $4.15 \times 10^{-4}$ & & 16372 & 5457 \\
FRO 1 & $3.04 \times 10^{-5}$ & $1.52 \times 10^{-4}$ & & 88952 & 17790 \\
FRO 2 & $1.85 \times 10^{-5}$ & $9.24 \times 10^{-5}$ & & 57876 & 11575 \\
FRO 3 & $2.56 \times 10^{-5}$ & $1.28 \times 10^{-4}$ & & 76372 & 15274 \\
\hline
\end{tabular}

Table 3. GMPEs considered in this study.

\begin{tabular}{llrrrll}
\hline Identifier & References & $\begin{array}{r}\text { Spectral period } \\
\text { range (s) }\end{array}$ & $\begin{array}{r}\text { Distance } \\
\text { range }(\mathrm{km})\end{array}$ & $\begin{array}{r}\text { Magnitude } \\
\text { range }\end{array}$ & $\begin{array}{l}\text { Distance } \\
\text { metrics }\end{array}$ & Origin of data \\
\hline BA08 & Boore and Atkinson (2008) & $0-10$ & $1-200$ & $5-8$ & $R_{\mathrm{JB}}$ & California, Taiwan \\
CB08 & Campbell and Bozorgnia (2008) & $0-10$ & $0-200$ & $4-8.5$ & $R_{\text {Rup }}$ & California, Taiwan \\
CF08 & Cauzzi and Faccioli (2008) & $0.01-20$ & $6-150$ & $5-7.2$ & $R_{\text {Focal }}$ & World crustal regions \\
ZH06 & Zhao et al. (2006) & $0-5$ & $0.4-300$ & $5-8.4$ & $R_{\text {Rup }}$ & Japan Crustal regions \\
\hline
\end{tabular}

2. The seismogenic depth: two seismogenic depths are considered at 15 and $20 \mathrm{~km}$ with equal weights based on both the recorded instrumental seismicity (Edel et al., 2006) and the interpretation of a crustal-scale seismic profile (DEKORP-ECORS, Brun et al., 1992). This parameter impacts the width of the fault, hence its area, therefore impacting the maximum magnitude and the moment rate budget.

3. The geometry of faults at depth: we explore two values of the faults' dip angle with the same weight.

4. The distribution of seismicity on faults: characteristic and GR earthquake magnitude distributions are attributed the same weight in the logic tree. There is no information in the region that could be used to justify the use of one approach rather than the other.

5. Slip rate: equal weights are attributed to the lower and higher slip rate values assessed from the vertical displacements of the geological markers described in Nivière et al. (2008) (see Part 1, Jomard et al., 2017).

6. Ground motion prediction equations (GMPEs): four equations widely used in PSHA applications are considered in this exercise (Table 3). These equations are valid for the range of magnitude and distance relevant for our study and representative of several ground motion data sets. These equations use different distance metrics: the shortest distance to the rupture $R_{\text {Rup }}$, the shortest distance to the projection of the rupture at the surface $R_{\mathrm{JB}}$, and the distance to the hypocenter $R_{\text {Focal }}$. The Vs30 parameter (mean shear wave velocity in the upper $30 \mathrm{~m}$ of the soil column) is set at $600 \mathrm{~m} \mathrm{~s}^{-1}$ to represent the sedimentary conditions of the URG.

All input parameters of faults for each branch of the logic tree and the results of the hazard calculation are provided in the Supplement.

\section{Results}

Figure 2a presents the weighted mean uniform hazard spectra (UHS) at a 10000 -year return period for each GMPE, resulting from the exploration of the logic tree (Fig. 1). The use of four GMPE affects the UHS level strongly, inducing an uncertainty in hazard levels ranging from 30 to $40 \%$ depending on the spectral frequency (Fig. 2a). Due to their different sensitivities to the parameters explored in the logic tree (see Sect. 5), each GMPE shows very different dispersions of the hazard results around their weighted means Fig. $2 b$.

Let us consider here only the results of a single branch of the logic tree (dotted black line in Fig. 2): active Rhine River and the West Rhenish faults, seismogenic depth of $15 \mathrm{~km}$, steepest dip of the faults, slowest slip rate, GutenbergRichter frequency-magnitude distribution and CB08 (Fig. 2a, 
(a)

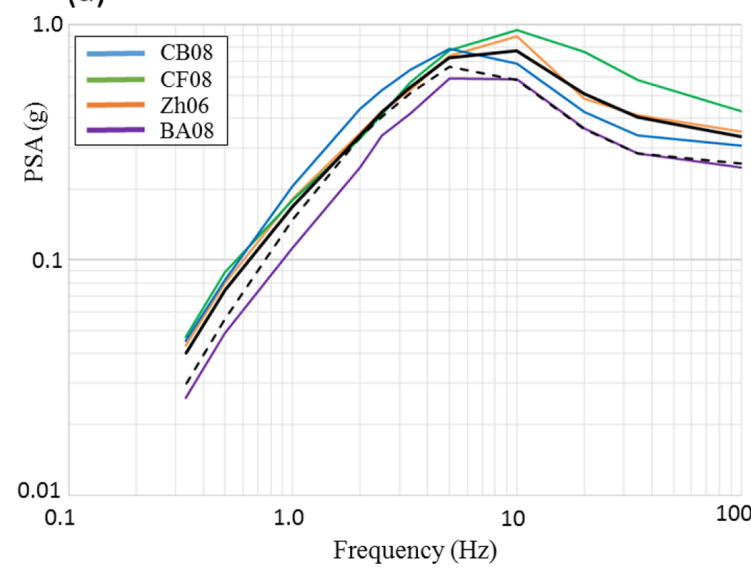

(b)

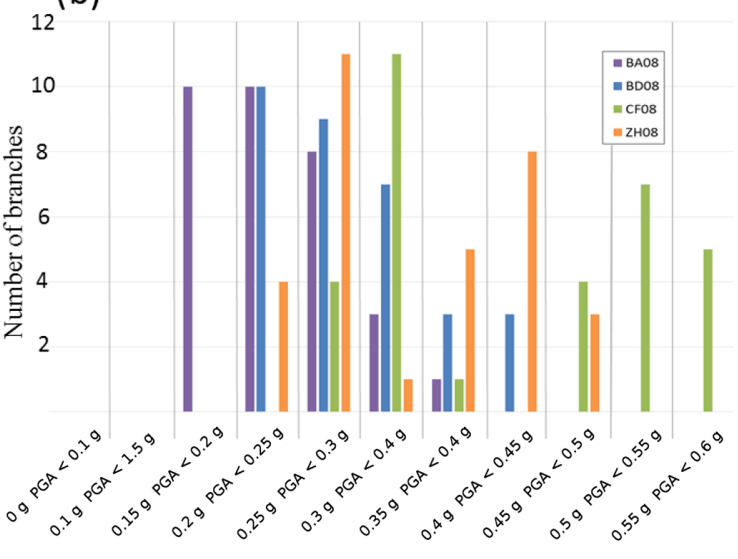

Figure 2. (a) Mean UHS for each GMPE for a return period of 10000 years (see Table 3 for the description of each GMPE). The black line is the mean of the four GMPEs. The dotted black line is the UHS of the branch used for the sensitivity analysis (see text for detail). (b) Dispersion of PGA at 10000 for each GMPE branch resulting from the exploration of epistemic uncertainties shown in Fig. 1.

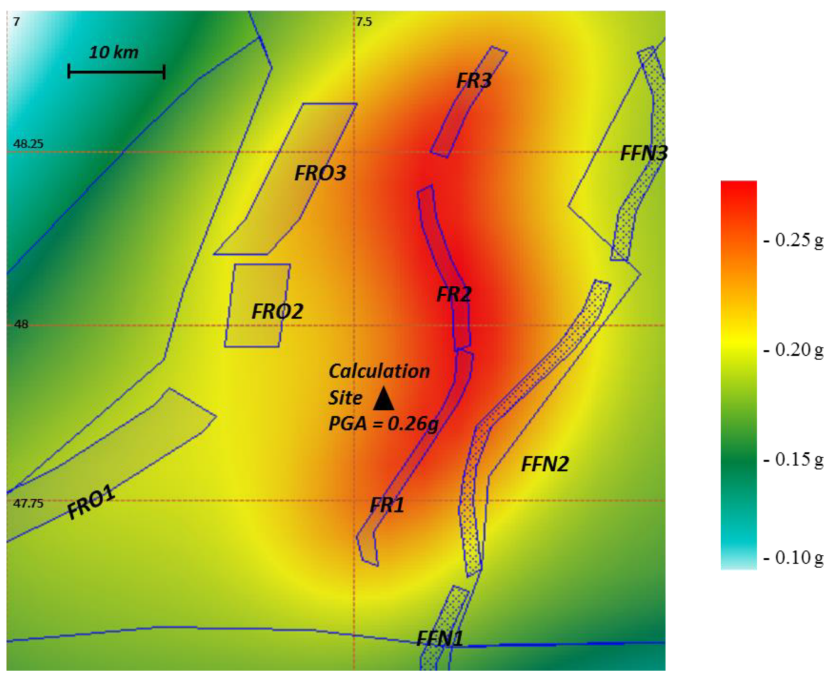

Figure 3. PGA seismic hazard map at a return period of 10000 years for the reference logic tree branch: active Rhine River fault, seismogenic depth of $15 \mathrm{~km}$, steepest dip for the faults, low slip rate values for the faults, Gutenberg-Richter MFD and the CB08 GMPE. Polygons represent the fault projections at the surface of the modelled faults (hachured polygons indicate the faults sources that are considered inactive in this calculation). Contours of the background area source are shown as well. Figure produced with the CRISIS2015 software, Ordaz et al. (2014). FR is Rhine River fault, FFN is Black Forest fault and FRO is West Rhenish fault.

dotted line). As Fig. 3 shows, a fault-based PSHA at 10000 year return periods leads to a higher level of hazard for sites located close to the most active faults. In order to further highlight the faults' contribution, let us compare disaggregation of the hazard for this branch at 475 and 10 000-year return period for peak ground acceleration (PGA; 0.06 and
$0.26 \mathrm{~g}$, respectively). Figure 4a shows that, at a 475 -year return period, more than $70 \%$ of the hazard is controlled by events in the 5.0-5.5 magnitude range located at less than $40 \mathrm{~km}$ from the site. Hazard levels are thus entirely controlled by the activity rates modelled in the background derived from the earthquake catalogue. In this case, the way in which the background region is modelled becomes paramount. On the contrary at a 10000 -year return period, which is the focus of this paper, hazard levels at the site are predominantly controlled by the larger magnitude events which occur on the faults in our model. In this case, the main fault contributing to the hazard is the Rhine River fault, which is $7 \mathrm{~km}$ away from the site of interest, with magnitude 6.0 or greater events occurring roughly every 10000 years (Table 2). Note, however, that even at this target probability level, earthquakes modelled in the background region still contribute up to $28 \%$ (Fig. 4b) of the hazard at the site of interest.

\section{Sensitivity study}

In order to quantify the impact of each epistemic uncertainty explored, we perform a sensitivity study using the same branch of the logic tree: active Rhine River fault and the West Rhenish faults, seismogenic depth of $15 \mathrm{~km}$, steepest dip of the faults, slowest slip rate, Gutenberg-Richter frequencymagnitude distribution.

\subsection{Shape of the MFD (Fig. 5a)}

The characteristic earthquake MFD leads to a spectral acceleration around 5\% lower than the GR MFD for this target probability level, the site of interest and the fault's characteristics considered in this exercise (Fig. 5a). 


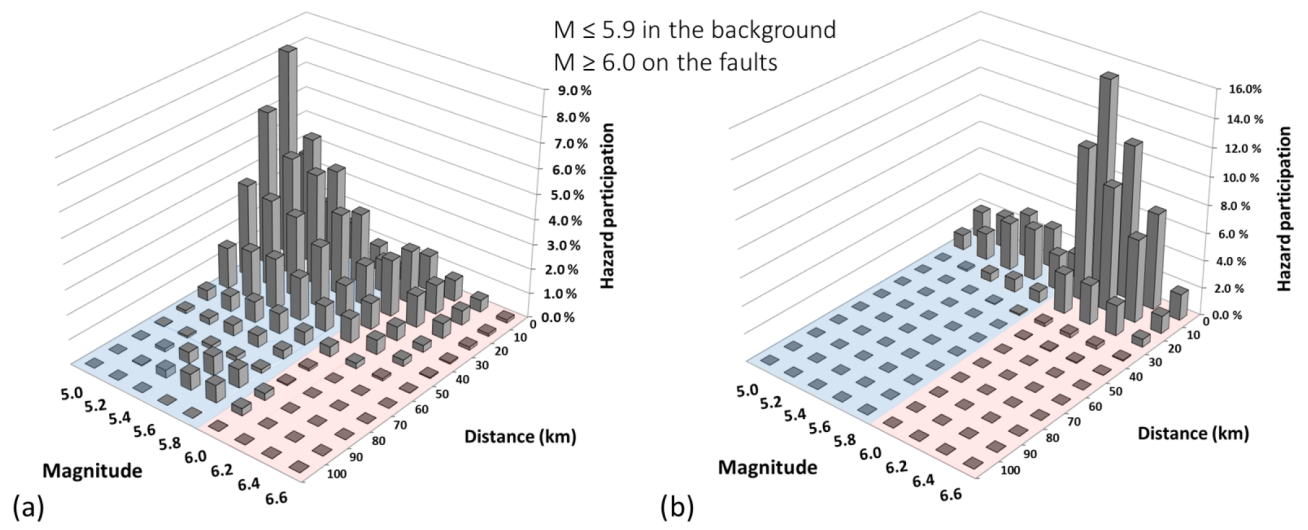

Figure 4. Seismic hazard disaggregation for PGA at return periods of (a) 475 years (PGA $=0.06 \mathrm{~g})$ and (b) 10000 years (PGA $=0.27 \mathrm{~g}$ ). Branch of the logic tree: active Rhine River fault, seismogenic depth of $15 \mathrm{~km}$, steepest dip of the faults, slowest slip rate, Gutenberg-Richter frequency-magnitude distribution and CB08.
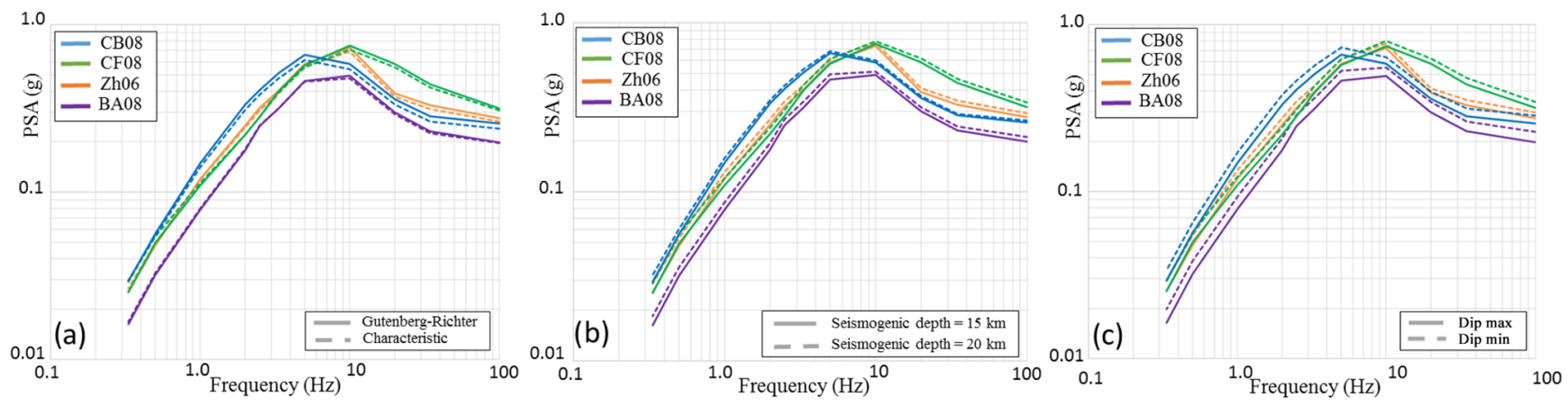

Figure 5. Impact of the different uncertainties explored in the logic tree on the UHS at 10000 years for the site of interest. (a) Shape of the MFD, (b) seismologic depth and (c) dip of the faults. The UHS of the reference branch is the solid lines in all figures.

\subsection{Geometry at depth (Fig. 5b and c)}

An increase in seismogenic depth and a reduction of the fault dip both lead to an increase of fault surface area, hence an increase of the earthquake rates modelled on the faults (see Eq. 5). Figure 5b shows that the increase in seismogenic depth increases the UHS by $5 \%$.

The reduction of the fault dip leads to a 10 to $15 \%$ increase in the UHS (Fig. 5c). Given the position of the site compared to the Rhine River fault (Fig. 3), the source-to-site distance is reduced for all metrics and the earthquake rate increases. Both effects induce a higher UHS at the site of interest.

\subsection{Deformation model (Fig. 6)}

Figure 6 shows that hazard levels at the site of interest are around 5 to $10 \%$ higher when the activity is considered on the Rhine River fault compared to the branch where the activity is on the Black Forest fault. In spite of its lower maximum magnitude and slip rate, the Rhine River fault is located closer to the site of interest and thus induces higher hazard at the site.

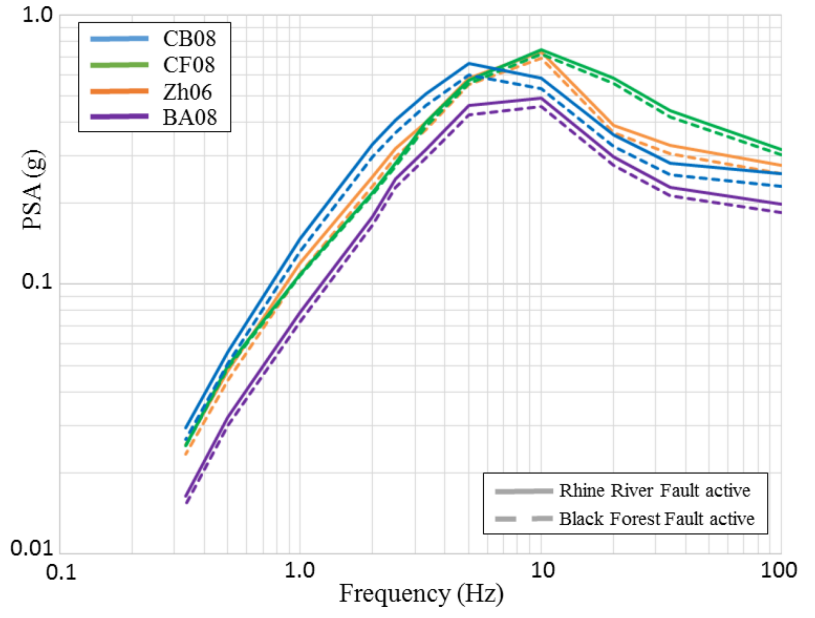

Figure 6. UHS at a 10000 -year return period considering four GMPEs: CB08, CF08, ZH06 and BA08 (see Table 3 for references). Seismogenic depth of $15 \mathrm{~km}$, the steepest dip of faults, the slowest slip rate, a Gutenberg-Richter frequency-magnitude distribution. 


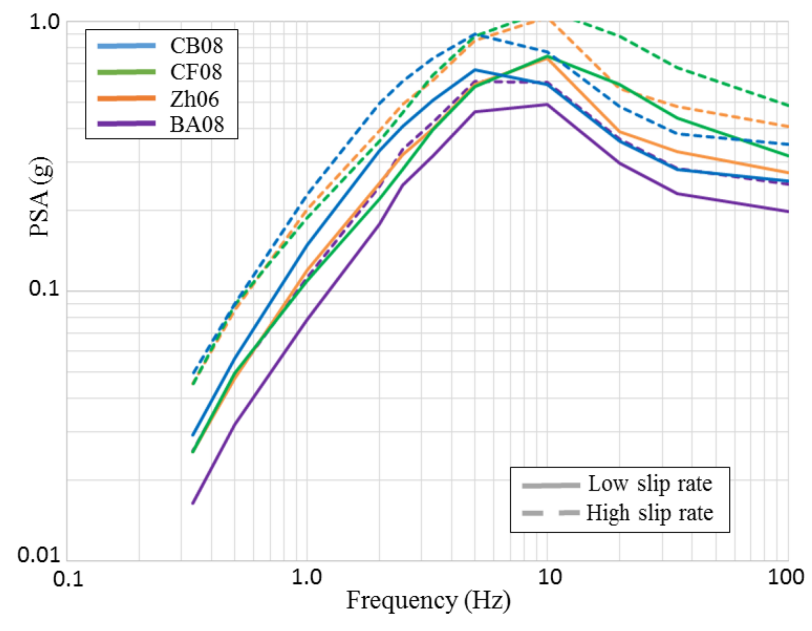

Figure 7. Comparison of UHS based on the Rhine River fault geodynamic model considering two slip rate values. Seismogenic depth of $15 \mathrm{~km}$, steepest dip of faults, a Gutenberg-Richter frequencymagnitude distribution.

\subsection{Slip rate (Fig. 7)}

Uncertainty in the slip rate estimates of faults on the other hand, which in moderate seismicity regions is often high, leads to considerable dispersion of the resulting hazard levels. For the case of the Rhine River fault, for example, an increase in slip rate from 0.04 to $0.1 \mathrm{~mm} \mathrm{yr}^{-1}$ results in a 2.5fold increase in seismic productivity (Table 2) and a roughly 40 to $50 \%$ increase in hazard levels (Fig. 7) depending on the GMPE. In many hazard studies, the selection of GMPE is the largest source of variability of the hazard level (Bommer et al., 2005). However, in this study the slip rate of the Rhine River fault induces a variability of the result of the same order of magnitude or even higher. Therefore, reducing epistemic uncertainty on the slip rate of faults is as important as reducing epistemic uncertainties in the choice of GMPE when fault-based PSHA is performed at this site.

\section{Conclusion}

The exercise conducted in this paper shows that the seismic hazard at a 10000 -year return period for the Fessenheim nuclear power plant site is mainly controlled by the activity of the Rhine River and Black Forest faults. Since our site of study is very close to the Rhine River fault, the result of the hazard calculation is highly dependent on the input parameters characterizing the seismic potential of this fault. This study highlights the slip rate attributed to the Rhine River fault and the choice of GMPE as the main sources of the variability of the seismic hazard. The uncertainty on the slip rate of the Rhine River fault leads to a $40 \%$ variability of the hazard at 10000 years, while uncertainties in the shape of the MFD and the geometry at depth induce a 10 to $15 \%$ variabil- ity of the hazard. This study has clearly pointed out the need to better constrain the slip rates of faults in the vicinity of the site and to choose GMPEs that are as much as possible based on data recorded in close proximity to faults in order to better constrain the hazard assessment at the site.

\section{Perspectives}

The fault-based PSHA will need to evolve towards more realistic rupture scenarios. The 2016 earthquakes (M 7.8 Kaikoura multiple segment rupture in New Zealand, $M$ 6-6.5 sequence in central Italy and $M$ 6.5-7 Kumamoto triplet in Japan) remind us that the representation of faults in our models is still too simplistic. Complex rupture scenarios have occurred and should be properly accounted for in more realistic fault-based approaches. Moreover, future hazard models should aim to take into account the complexity of the regional deformation and assess the part of strike-slip deformation suggested by some focal mechanisms and not considered in this study.

In the present paper, the background seismicity was implemented in a very basic manner. We have limited the maximum magnitude that can occur in the background at 6.0. However, we stress that blind faults, capable of generating $M>6.0$ known to be present at depth (Part 1 of this paper), will somehow need to be accounted for.

A study is presently ongoing in the Upper Rhine Graben to better constrain the recent activity of the fault system (Baize et al., 2016) based on geophysical and palaeoseismological investigations. An additional study (Del Gaudio et al., 2016) is modelling ground motion in the Upper Rhine Graben with the help of the empirical green function approach (Del Gaudio et al., 2015). It is hoped that these studies will provide new insights for reducing epistemic uncertainty in faultbased PSHA of the Upper Rhine Graben.

Data availability. All the fault data used in this study are available in the faults database presented in Part 1 (Jomard et al., 2017).

\section{The Supplement related to this article is available online at https://doi.org/10.5194/nhess-17-1585-2017- supplement.}

Competing interests. The authors declare that they have no conflict of interest.

Special issue statement. This article is part of the special issue "Linking faults to seismic hazard assessment in Europe". It is not associated with a conference. 
Acknowledgements. The work presented in this paper was prepared for a master thesis project, which was jointly funded by IRSN and ANR-11-RSNR-0022 SINAPS@ project. We would like to thank Julian Garcia-Mayordomo and the anonymous referee for their valuable comments and remarks that helped to improve this article to a great extent.

Edited by: Francesco Visini

Reviewed by: Julian Garcia-Mayordomo and one anonymous referee

\section{References}

Baize, S., Cushing, E. M., Lemeille, F., and Jomard, H.: Updated seismotectonic zoning scheme of Metropolitan France, with reference to geologic and seismotectonic data, B. Soc. Geol. Fr., 184, 225-259, https://doi.org/10.2113/gssgfbull.184.3.225, 2013.

Baize, S., Reicherter, K., Thomas, J., Chartier, T., and Cushing, E. M.: Towards a Fault-based SHA in the Southern Upper Rhine Graben, EGU General Assembly, Vienna, Austria, 17-22 April 2016, EGU2016-14458, 2016.

Bommer, J. J. and Crowley, H.: The Purpose and Definition of the Minimum Magnitude Limit in PSHA Calculations, Seismol. Res. Lett., 88, https://doi.org/10.1785/0220170015, 2017.

Bommer, J. J., Scherbaum, F., Bungum, H., Cotton, F., Sabetta, F., and Abrahamson, N. A.: On the Use of Logic Trees for Ground-Motion Prediction Equations in SeismicHazard Analysis, B. Seismol. Soc. Am., 95, 377-389, https://doi.org/10.1785/0120040073, 2005.

Boore, D. M. and Atkinson, G. M.: Ground-motion prediction equations for the average horizontal component of PGA, PGV, and $5 \%$-damped PSA at spectral periods between $0.01 \mathrm{~s}$ and $10.0 \mathrm{~s}$, Earthq. Spectra, 24, 99-138, https://doi.org/10.1193/1.2830434, 2008.

Brun, J. P., Gutscher, M.-A., and dekorp-ecors Teams: Deep crustal structure of the Rhine Graben from dekorp-ecors seismic reflection data: A summary, Tectonophysics, 208, 139-147, https://doi.org/10.1016/0040-1951(92)90340-C, 1992.

Campbell, K. W. and Bozorgnia, Y.: NGA ground motion model for the geometric mean horizontal component of PGA, PGV, PGD and 5\% damped linear elastic response spectra for periods ranging from 0.01 to $10 \mathrm{~s}$, Earthq. Spectra, 24, 139-171, https://doi.org/10.1193/1.2857546, 2008.

Cauzzi, C. and Faccioli, E.: Broadband (0.05 to $20 \mathrm{~s})$ prediction of displacement response spectra based on worldwide digital records, J. Seismol., 12, 453-475, https://doi.org/10.1007/s10950-008-9098-y, 2008.

CEA/LDG: Data file of French earthquakes from 1962 and on, Laboratoire de Détection et de Géophysique, Bruyères-le-Châtel, France, 2011.

Cornell, C. A.: Engineering seismic risk analysis, B. Seismol. Soc. Am., 58, 1583-1606, 1968.

Cosentino, P., Ficarra, V., and Luzio, D.: Truncated exponential frequency-magnitude relationship in earthquake statistics, B. Seismol. Soc. Am., 67, 1615-1623, 1977.
Del Gaudio, S., Causse, M., and Festa, G.: Broad-band strong motion simulations coupling k-square kinematic source models with empirical Green's functions: the 2009 L'Aquila earthquake, Geophys. J. Int., 203, 720-736, https://doi.org/10.1093/gji/ggv325, 2015.

Del Gaudio, S., Hok, S., Causse, M., Festa, G., and Lancieri, M.: Near fault broadband ground motion simulation with empirical Green's functions: the Upper Rhine Graben case study, EGU General Assembly, Vienna, Austria, 17-22 April 2016, EGU2016-15403, 2016.

Edel, J. B., Whitechurch, H., and Diraison, M.: Seismicity wedge beneath the Upper Rhine Graben due to backwards Alpine push?, Tectonophysics, 428, 49-64, https://doi.org/10.1016/j.tecto.2006.08.009, 2006.

Fujiwara, H., Kawai, S., Aoi, S., Morikawa, N., Senna, S., Kudo, N., Ooi, M., Hao, K. X., Wakamatsu, K., Ishikawa, Y., Okumura, T., Ishii, T., Matsushima, S., Hayakawa, Y., Toyama, N., and Narita, A.: Technical reports on national seismic hazard maps for Japan, National Res. Inst. for Earth Science and Disaster Prevention, Technical Note, 336, 52 pp., 2009.

Gutenberg, B. and Richter, C. F.: Seismicity of the Earth, Princeton University Press, Princeton, New Jersey, 310 pp., 1954.

Hanks, T. C., and Kanamori, H.: A moment magnitude scale, J. Geophys. Res., 84, 2348-2350, https://doi.org/10.1029/JB084iB05p02348, 1979.

IAEA: Safety Standards: Seismic Hazards in Site Evaluation for Nuclear Installations, IAEA, Series No. SSG-9, 56 pp., 2010.

Jomard, H., Cushing, E. M., Palumbo, L., Baize, S., David, C., and Chartier, T.: Transposing an active fault database into a seismic hazard fault model for nuclear facilities - Part 1: Building a database of potentially active faults (BDFA) for metropolitan France, Nat. Hazards Earth Syst. Sci., 17, 1573-1584, https://doi.org/10.5194/nhess-17-1573-2017, 2017.

McGuire, R. K.: FORTRAN computer program for seismic risk analysis, US Geological Survey, Open-File Report 76-67, 90 pp., 1976.

Nivière, B., Bruestle, A., Bertrand, G., Carretier, S., Behrmann, J., and Gourry, J. C.: Active tectonics of the southeastern Upper Rhine Graben, Freiburg area (Germany), Quaternary Sci. Rev., 27, 541-555, https://doi.org/10.1016/j.quascirev.2007.11.018, 2008.

Ordaz, M., Martinelli, F., Aguilar, A., Arboleda, J., Meletti, C., and D'Amico, V.: CRISIS 2014, Program for computing seismic hazard, Instituto de Ingeniería, Universidad Nacional Autónoma de México, Mexico, 2014.

Rotstein, Y. and Schaming, M.: The Upper Rhine Graben (URG) revisited: Miocene transtension and transpression account for the observed first-order structures, Tectonics, 30, TC3007, https://doi.org/10.1029/2010TC002767, 2011.

Schumacher, M. E.: Upper Rhine Graben: Role of preexisting structures during rift evolution, Tectonics, 21, 6-1-6-17, https://doi.org/10.1029/2001TC900022, 2002.

Stucchi, M., Rovida, A., Capera, A. G., Alexandre, P., Camelbeeck, T., Demircioglu, M. B., Gasperini, P., Kouskouna, V., Musson, R. M. W., Radulian, M., Vilanova, S., Baumont, D., Bungum, H., Fäh, D., Lenhardt, W., Makropoulos, K., Martinez Solares, J. M., Scotti, O., Živčić, M., Albini, P., Batllo, J., Papaioannou, C., Tatevossian, R., Locati, M., Meletti, C., Viganò, D., Giardini, D., and Sesetyan, K.: The SHARE European earth- 
quake catalogue (SHEEC) 1000-1899, J. Seismol., 17, 523-544, https://doi.org/10.1007/s10950-012-9335-2, 2013.

Valentini, A., Visini, F., and Pace, B.: Integrating faults and past earthquakes into a probabilistic seismic hazard model for peninsular Italy, Nat. Hazards Earth Syst. Sci. Discuss., https://doi.org/10.5194/nhess-2017-41, in review, 2017.

Wang, Y.-J., Chan, C.-H., Lee, Y.-T., Ma, K.-F., Shyu, J.-H., Rau, R.-J., and Cheng, C.-T.: Probabilistic seismic hazard assessments for Taiwan, Terr. Atmos. Ocean. Sci., 27, 325-340, https://doi.org/10.3319/TAO.2016.05.03.01(TEM), 2016.

Wells, D. L. and Coppersmith, K. J.: New empirical relationships among magnitude, rupture length, rupture width, rupture area, and surface displacement, B. Seismol. Soc. Am., 84, 974-1002, 1994.
Wesnousky, S. G.: Earthquakes, Quaternary faults, and seismic hazard in California, J. Geophys. Res., 91, 12587-12631, 1986.

Zhao, J. X., Zhang, J., Asano, A., Ohno, Y., Oouchi, T., Takahashi, T., Ogawa, H., Irikura, K., Thio H. K., Somerville, P. G., Fukushima, Y., and Fukushima, Y.: Attenuation relations of strong ground motion in Japan using site classification based on predominant period, B. Seismol. Soc. Am., 96, 898-913, https://doi.org/10.1785/0120050122, 2006. 